\title{
Diabetes and its management
}

\author{
Aarti Seherawat \\ Department of Zoology, University of Delhi, India
}

\begin{abstract}
In the past decade there has been a rapid expansion in the number of drugs available to treat Diabetes. Different classes of antidiabetic drugs are available with each having different pharmacological mechanism of action. This review presents the commercially available drugs for management of diabetes. Role of various antidiabetic drugs and their side effects are discussed.
\end{abstract}

Keywords: Diabetes, Type-1 diabetes, Type-2 diabetes, antidiabetic drugs.

\subsection{Therapeutic approach}

\section{Introduction}

\subsubsection{Type 1 diabetes}

Known as insulin dependent diabetes, or juvenile- onset diabetes, results from a cellular-mediated autoimmune destruction of the $\beta$-cells of the pancreas. The peak age of presentation in children is around the age of puberty. The symptoms and signs are related to the presence of hyperglycaemia and the resulting effects on fluid and electrolyte balance, generally include polyuria, polydipsia, polyphagia, weight loss, and blurred vision. It is associated with ketoacidosis, with the symptoms of abdominal pain, nausea, and vomiting. Variable effects on mental status may be seen, ranging from slight drowsiness to profound lethargy and even coma if the condition has been untreated for a brief period of time.

\subsubsection{Type 2 diabetes}

Early diagnosis and intervention have at least the potential of reducing the complications to 20 to $50 \%$. It is estimated that in up to $50 \%$ of affected people the disease is undiagnosed, with an estimated lag of 5 to 7 years between the onset of diabetes and its diagnosis [1]. Subjects with undiagnosed type 2 diabetes are at significantly increased risk for coronary heart disease, stroke, and peripheral vascular disease evident seems. Thus this delay in diagnosis of type 2 diabetes causes an increase in microvascular and macrovascular disease. In addition affected individuals have a greater likelihood of having dyslipidemia, hypertension, and obesity.

\subsubsection{Insulin Resistance and the Risk of Type 2 Diabetes}

Insulin resistance plays a major role in the development of glucose intolerance and diabetes infact resistance is present years before the onset of diabetes [2]. Insulin resistance is manifested by decreased insulin - stimulated glucose transport and metabolism in adipocytes and skeletal muscle and by impaired suppression of hepatic glucose output. Insulin sensitivity is influenced by a number of factors including age [3], weight, ethnicity, body fat (especially abdominal), physical activity, and medications. There is also a strong influence of environmental factor on the genetic predisposition to insulin resistance and therefore to diabetes [4].

\subsubsection{Obesity and Type 2 Diabetes}

A close association between obesity and insulin resistance is seen in all ethnic groups and is found across the full range of body weights, across all ages, and in both sexes [5]. A number of large epidemiological studies showed that the risk for diabetes, and presumably insulin resistance, rise as body fat content increases from the very lean to the very obese [6].

\subsection{Type 1 Diabetes}

\section{Pharmacotherapy Of Diabetes}

\subsubsection{Immunotherapy}

At the onset of type 1 diabetes, a major clinical research goal is the prevention of further $\beta$ cell destruction. At present there is no proven safe and effective therapy to prevent such further destruction or to prevent the development of type 1 diabetes in those at risk (eg. Genetically). There are various therapies to combat diabetes complications like Immunosuppression, Immunologic vaccination, Pancreatic transplantation. Replacement of patient's Islet of langerhans either by pancreas transplantation or by isolated islet transplantation is the only treatment of diabetes mellitus that achieves insulin dependent, constant normoglycaemic state and avoidance of hypoglycaemic episodes [7]. Despite significant progress made, whole pancreas transplantation is still associated with preoperative mortality and significant morbidity [8]. Other 
technical obstacles faced are immune rejection, inappropriate blood supply to the allograft and the risk of activating the digestive enzymes of the exocrine portion. Islet cell transplantation for patients with diabetes has shown considerable promise for achieving insulin dependence [9]. Also it is a minimally invasive procedure, in which islets can be perfused percutaneously into the liver via the portal vein with local anesthesia [10].

\subsubsection{Insulin}

In the past, insulin for human use was obtained from animal sources- beef and pig. With advances in recombinant DNA technology, it is now possible to produce large quantities of insulin with an amino acid structure identical to that of human insulin using laboratory strains of Escherichia coli bacteria (Humulin) or yeast (Novolin). It can be created by chemically modified beef or pork insulin (semi synthetic insulin) [11]. All forms of insulin have identical physiological effects only differ in the rapidity of onset of action, the time from injection to peak action, and the duration of action depending on the chemical nature of the particular insulin preparation [12]. Originally, insulin was administered intramuscularly, but soon subcutaneous injections were found to be equally effective and less painful [13]. Not only is the variety of insulin preparations available growing, but also the methods for administering insulin.

\subsubsection{Subcutaneous Delivery}

Pre-filled insulin pens: To avoid the risk of dosage errors associated with the use of syringe injection process [14], insulin pens were introduced. These pens combined the insulin container and syringe in a single unit and had smaller-gauge needles [15]. Insulin pump: An alternative method of delivering insulin is by an external mechanical pump. This approach involves the administration of a rapid acting insulin preparations delivered by continuous subcutaneous infusion through a catheter usually inserted into the subcutaneous tissues of the anterior abdominal wall. It is composed of a reservoir, a-battery-operated pump, and a computer chip. Advantages of continuous subcutaneous insulin infusion (in which a portable electromechanical pump is used) compared with multiple daily injections have been demonstrated, including decreased risk of hypoglycaemia [16], improved control of morning glucose levels (the 'dawn phenomenon') [17] and a lower risk of activityinduced hypoglycaemia [18]. At present, the pump is the closest device on the market to an artificial pancreas.

\subsubsection{Non-invasive Insulin Delivery System: Inhaled insulin}

This method delivers insulin directly to the alveoli where it is readily absorbed into the blood supply and has a rapid onset of action [19]. Exubera ${ }^{\circledR}$ inhaled insulin: Exubera is insulin powder packed into blisters with different dosages and a specialized inhaler. It is not recommended in patients with asthma, bronchitis, or emphysema. AERx insulin diabetes management system: This system delivers a liquid form of human insulin [20]. AIR particle technology: large porous microparticles with density less than $0.4 \mathrm{~g} / \mathrm{cm}^{3}$ are used to deposit into the deep lung region. Technosphere insulin system: This system consists of an ordered lattice array of spherical particles and $18 \%$ insulin formulated as a crystalline dry powder. Buccal insulin: Insulin preparation sprayed into mouth via a metered dose inhaler. Oral-lyn ${ }^{\mathrm{TM}}$ is a human recombinant insulin (Humulin R) with added enhancers, stabilizers, and a nonchloroflurocarbon propellant [21].

\subsubsection{Oral insulin}

Oral administration of insulin is very difficult, [22] hexylisulin monoconjugate 2 (HIM2) by Nobex corporation and Elige ${ }^{\circledR}$ technology by Emisphere, provides synthetic chemical compounds known as EMISPHERE $^{\circledR}$ delivery agents, or "carriers". Emisphere insulin tablets have been tested in phase I/II trials [23]. Insulin therapy affords effective glycaemic control, yet its serious disadvantages hypoglycaemia, weight gain insulin allergy and worsening of retinopathy [24] stimulated appetite contributing to weight gain limit its usage.

\subsection{Type 2 Diabetes}

The revolution in the treatment of type 2 diabetes since 1995 in the United States has been driven by the release of multiple new classes of drugs (Table 1).

Table 1: Therapeutic agents for diabetes mellitus

\begin{tabular}{|l|l|l|l|l|}
\hline Drug Class & Eg. & Mechanism & $\begin{array}{l}\text { Molecular } \\
\text { Target }\end{array}$ & Adverse Effect \\
\hline Sulphonylureas & $\begin{array}{l}\text { Tolbutamide, } \\
\text { Ge }\end{array}$ & $\begin{array}{l}\text { Enhance insulin release from islets of } \\
\text { langerhans }\end{array}$ & $\begin{array}{l}\text { Insulin } \\
\text { receptor }\end{array}$ & $\begin{array}{l}\text { Hypoglycemic } \\
\text { weight gain }\end{array}$ \\
\hline Biguanides & Metformin & $\begin{array}{l}\text { Inhibits hepatic gluconeogenesis } \\
\text { (enhances tissue sensitivity to } \\
\text { insulin)initially derived from medicinal } \\
\text { plant Galega officinalis }\end{array}$ & $\begin{array}{l}\text { GI disturbances and lactic } \\
\text { acidosis }\end{array}$ \\
\hline Thiazolidinediones & Pioglitazone & Insulin sensitizer that helps the body to PPAR $\gamma$ & Weight gain and anaemia \\
\hline
\end{tabular}


Diabetes and its management

\begin{tabular}{|l|l|l|l|l|}
\hline & & $\begin{array}{l}\text { use its own insulin (particularly effective } \\
\text { in type -II diabetes) }\end{array}$ & \\
\hline $\begin{array}{l}\alpha \text {-glucosidase inhibitor } \\
\text { (oral drug)best use in } \\
\text { combination therapy }\end{array}$ & Acarbose & $\begin{array}{l}\text { Decrease absorption of glucose from } \\
\text { intestine }\end{array}$ & $\begin{array}{l}\alpha \text {-glucoside } \\
\text { (maltase) }\end{array}$ & GI Disturbances \\
\hline GLP-1 & $\begin{array}{l}\text { Glucagen } \\
\text { like peptides }\end{array}$ & Toxicity is poorly understood & & \\
\hline
\end{tabular}

\subsubsection{Insulin Secretagogues}

\subsubsection{Sulphonylureas (SUs)}

The first line of therapy in non-obese patients were first introduced in the 1950s [25]. SUs act to close potassium ATPase channels in the presence of glucose in pancreatic $\beta$ cells which leads depolarization and insulin secretion [26]. The first generation SUs (tolbutamide and chlorpropamide), and were later followed by newer second generation SUs (glibenclamide and gliclazide) in the 1970s and 1980s [27]. With side effects including weight gain (on average 1-4 kg) and hypoglycaemia, they do not lead to an improvement in blood pressure and have no consistent effect on lipids [28]. Controversially, it has been proposed that patients receiving treatment with SUs are at increased risk of macrovascular disease. Also an increased mortality was observed in patients who treated with the SUs and metformin combination [24]. A newer 'third generation' SU Glimepiride, shows greater selectivity for pancreatic K-ATPase channels, but is not known whether this leads to improvements in cardiovascular risk [29].

\subsubsection{Meglitinide Analogues}

Also known as non-SU secretagogues or prandial glucose regulators, the first meglitinide analogue repaglinide was introduced in the UK in 1998 developed from the non-sulphonylurea portion of glibenclamide. Later it was followed by nateglinide, a D-phenylalanine derivative. They have a similar mechanism of action to SUs, closing K-ATPase channels in pancreatic $\beta$ cells, but they do not stimulate insulin exocytosis from $\beta$ cells as done by the SUs [30]. Side-effect profiles are also similar to the SUs [31].

\subsubsection{Drugs Acting to Reduce Insulin Resistance}

\subsubsection{Biguanides}

Were originally developed from Galega Officialis, a traditional guanidine rich compound, which was used to treat diabetes in medieval times [32]. Three biguanide compounds (containing two linked guanidine rings); phenformin, metformin and buformin were introduced in the 1950s [33]. Only metformin remains in clinical use due to the risk of developing life threatening lactic acidosis and was introduced in the USA in 1995. Its principle antihyperglycaemic effect is thought to be reduction of hepatic gluconeogenesis, as a result of increased hepatic insulin sensitivity [34]. It is therefore dependent on the presence of circulating insulin and adequate $\beta$ cell function. Unless combined with SUs, metformin does not cause severe hypoglycaemia as it is an 'insulin sensitizer' and does not stimulate insulin secretion [35]. In fact, metformin leads to a reduction in hyperinsulinaemia, a factor proposed to be involved in the pathogenesis of macrovascular disease [36]. Metformin is the first line oral antidiabetic agent in the obese, as unlike the SUs, it does not lead to significant weight gain with the only main limiting side-effects as gastrointestinal [37]. Other benefits of metformin, contribute to its cardiovascular effects, improvement in lipid profile, stabilization of weight, increased fibrinolysis, and reduced plasminogen activator inhibitor-1 (PAI-1) and von Willibrand factor levels [38]. Also metformin reduce TGs, LDL-C and increase HDL-C [39].

\subsubsection{Thiazolidinediones (TZD)}

The first TZD troglitazone was introduced in the USA and Japan in 1997, but was subsequently withdrawn due to reports of hepatotoxicity [40]. Two TZDs pioglitazone and rosiglitazone, are now used and appear to have a much safer side-effect profile [41]. They are also known as Peroxisome Proliferator Activated Receptor (PPAR) gamma agonists after the nuclear receptor strongly expressed in adipose tissue on which they exert their effect. They improve insulin sensitivity by increasing transcription of various insulin sensitive genes, including those encoding Lipoprotein lipase, GLUT 4, and Fatty Acid Transport Protein, and they may also suppress hepatic gluconeogenesis [42]. The main side effect of the PPAR gamma agonists is fluid retention which leads to significant weight gain, a dilutional anemia, and obvious problems with fluid overload in patients with heart failure, in whom they are contraindicated [43]. In contrast to metformin the TZDs produce an increase in insulin sensitivity without weight loss, but have been shown to cause redistribution of adipose tissue with a reduction in visceral adiposity, a marker of insulin resistance [44]. 


\subsubsection{Drugs Delaying the Absorption of Glucose \\ 2.2.4.1. Alpha Glucosidase Inhibitors}

Acarbose, introduced in the early 1990s, is the only alpha glucosidase inhibitor (AGI) currently licensed for use. They inhibit brush border enzymes in the small intestine, which act to cleave oligo and disaccharides and delay the absorption of glucose [45]. Unfortunately, due to severe gastrointestinal sideeffects that result from increased delivery of oligosaccharides to the large intestine where they undergo fermentation by commensal bacteria leading to flatulence, diarrhea and abdominal discomfort, limits its use [46].

\subsubsection{New Medications that Effect Glycaemic Control}

Incertins such as glucagon-like peptide-1 (GLP-1) are naturally occurring gut hormones released in response to ingestion of food [47]. It is known that in type 2 diabetes the meal-stimulated circulating levels of GLP-1 are reduced. Thus GLP-1 seems an appropriate therapeutic agent in patients with type 2 diabetes. However, its utility as a pharmacologic agent is limited due to the short plasma half life (2min) before being degraded by dipeptidyl peptase IV (DPP-IV). Exenatide (Byetta ${ }^{\circledR}$ ) a synthetic GLP-1 analogue which has a longer half life because it is not recognized by DPP-IV. It is the synthetic version of exendin-4, an incretin mimetic isolated from the saliva of the Gila monster lizard [48]. Liraglutide (NN2211) is an acylated human GLP-1 analogue which binds noncovalently to albumin. It exhibits a more prolonged pharmacokinetic profile relative to native GLP-1 or exenatide. Similar to exenatide, nausea is the most common adverse effect associated with liraglutide administration. Other albumin-based GLP-1 analogue includes CJC-1131, a DPP-IVresistant GLP-1 analogue that forms a covalent bond with a single amino acid residue within human serum albumin, and Albugon, a recombinant albumin/GLP-1 hybrid protein [49]. Studies have suggested that Vildagliptin treatment might improve $\beta$ cell function [50]. Sitagliptin (MK-0431-Januvia ${ }^{\circledR}$ ) was approved for use in the US as monotherapy and in combination with Metformin or a TZD. Sitagliptin increased the postprandial rise in active GLP-1 concentrations [51]. Glyburide/ Metformin (Glucovance), rosiglitazone/ Metformin (Avandamet), glipizide/Metformin (Metaglip), and pioglitazone/ Metformin (Actospluamet) are four relatively some of the combination pills that are in the market to treat diabetes.

\section{Conclusion}

With the available known drugs, it seems to control diabetes to a great extent. There has been an increase in the number of drugs in recent years, some with complex metabolic properties and their antihyperglycaemic effects. Some of the drugs show promising effects with minimal side effects and provide a scope in management of diabetes.

\section{Refrences}

[1] M.I. Harris, C.C. Cowie, M.P. Stern, E.S. Boyko, G.E. Reiber, and P.H. Bennett, Diabetes in America. $2^{\text {nd }}$ edn. Washington DC: US Government Printing Office, 1995 (NIH publ. No. 95-1468).

[2] H. Himsworth, and R.B. Kerr, Insulin sensitive and insulin insensitive types of diabetes mellitus. Clinical Sciences, 4: b, 1939, 119152.

[3] G. Paolisso, M.R. Tagliamonte, M.R. Rizzo, and D. Giugliano, Advancing age and insulin resistance: new facts about an ancient history. European Journal of Clinical Investigation, 29, 1999, 758-769.

[4] Y. Hong, N.L.Pedersen, K. Brismar, and U. de Faire, Genetic and environmental architecture of the features of the insulin resistance syndrome. American Journal of Human Genetics, 60, 1997, 143-152.

[5] A.J.Bergman, C.Stevens, Y.Zhou, B. Yi, M.Laethem, and M.De Smet, Pharmacokinetics and pharmacodynamics of sitagliptin, an inhibitor of dipeptidyl peptidase-IV, in healthy subjects: results from two randomized, double-blind, placebocontrolled studies with single oral dose. Clin. Pharmacol. Ther., 78,2005, 675-688.

[6] F.B.Hu, J.E. Manson, and M.J.Stampfer, Diet, lifestyle, and the risk of type 2 diabetes mellitus in women. N. Eng. J. Med., 345, 2001, 790-797.

[7] D.E.Sutherland, P.F. Gores, A.C. Farney, D.C.Wahoff, A.J. Matas, D.L.Dunn, R.W.Gruessner, and J.S.Najarain, Evolution of kidney, pancreas, and islet transplantation of patients with diabetes at University of Minnesota. American Journal of Surgery, 166, 1993, 456-491.

[8] C.L.Manske, Risks and benefits of kidney and pancreas transplantation for diabetes patients. Diabetes Care, 22, 1999, B114-120.

[9] P.E.Lacy, and D.W.Scharp, Islet transplantation in treating diabetes. Annual Review of Medicine, 37, 1986, 33-40.

[10] B.Weimar, K.Rauber, M.D.Brendel, R.G.Bretzel, and W.S.Rau, Percutaneous transhepatic catheterization of the portal vein: a combined CT-and fluoroscopy-guided technique. Cardiovascular Interv Radiology, 22, 2001, 342-344.

[11] D.C.Howey, A.Vaag, M.Hansson, J.Weng, E.Laurila, and L.Groop, Impaired insulin stimulated expression of the glycogen synthase gene in skeletal muscle of type 2 diabetic patients is acquired rather than inherited. Journal of Clinical Endocrinological Metabolism, 85 (4), 2000, 1584-1590.

[12] L.Vignati, J.Anderson, and R.Brunelle, Efficacy of [Lys (B28), Pro (B29)] human insulin in a year global randomized clinical trials. Diabetes, 43(1), 1994, 78.

[13] C.D.Saudek, Novel forms of insulin delivery. Endocrinological Metabolism Clinical, 26(3), 1997, 599-601.

[14] C.Coscelli, S.Lostia, and M.Lunette, Safety, efficacy, acceptability of a prefilled insulin pen in diabetes patients over 60 years old. Diabetes Research and Clinical Practice, 28, 1995, 173-177.

[15] N.J.Bohannon, Insulin delivery using pen devices. Simple touse tools may help young and old alike. Postrad. Med., 106(5), 1999, 57-64. 
[16] B.D. Bode, R.D.Steed, and P.C.Davidson, Reduction in severe hypoglycaemia with long term continuous subcutaneous insulin infusion in type 1 diabetes. Diabetes Care, 19(4), 1996, 324-327.

[17] V.A.Koivisto, H.Yki-Jarvinen, E.Helve, S.L.Karonen, and R.Pelkonen, Pathogenesis and prevention of the dawn phenomenon in diabetic patients treated with CSII. Diabetes, 35(1), 1986, 78-82.

[18] B.W.Bode, W.V.Tamborlane, and P.C.Davidson, Insulin pump therapy in the $21^{\text {st }}$ century: Strategies for successful use in adults, adolescents, and children with diabetes. Postgraduate Medicine, 111(5), 2002, 69-77.

[19] L.Heinemann, Alternative delivery routes: inhaled insulin. Diabetes Nut. Metabolism, 15(6), 2002, 417-422.

[20] L.S.Hermann, B.Scherste'n, and P.O.Bitze'n, Therapeutic comparison of metformin and sulfonylurea, alone and in various combinations. A double-blind controlled study. Diabetes Care, 17, 1994, 1100-1109.

[21] J.Guevara-Aguirre, M.Guevara, J.Saavedra, M.Mihic, and P.Modi, Oral spray insulin in treatment of type 2 diabetes: a comparison of efficacy of the oral spray insulin (oralin) with subcutaneous (SC) insulin injection, a proof of concept study. Diabetes Metabolism research Review, 20(6), 2004, 472-478.

[22] A.Hoffman, and E.Ziv, Pharmacokinetics considerations of new insulin formulations and routes of administration. Clinical Pharmacokinetics, 33(4), 1997, 285-301.

[23] D.Malkov, R.Angelo, H.Z.Wang, E.Flanders, H.Tang, and I.Gomez-orellana, Oral delivery of insulin with the Eligen technology: mechanistic study. Current Drug Deliv., 2(2), 2005,191-197.

[24] UK Prospective Diabetes Study Group, Effect of intensive blood-glucose control with metformin on complications in overweight patients with type 2 diabetes (UKPDS-34). Lancet, 352, 1998, 854-865.

[25] D.L.Kennedy, J.M.Piper, and C.Baum, Trends in the use of oral hypoglycemic agents, 1964-1986. Diabetes Care, 11, 1988, 558562.

[26] F.M.Ashcroft, and P.Rorsman, Electrophysiology of the pancreatic beta-cell. Prog. Biophys. Mol. Biol., 54, 1989, 87-143.

[27] J.E.Gerich, Oral hypoglycaemic agents. N. Engl. J. Med., 321, 1989, 1231-1245.

[28] C.J.Bailey, and C.Day, Antidiabetic drugs. Br. J. Cardiol., 10, 2003,128-136.

[29] H.D.Langtry, and J.A.Balfour, Glimepiride: a review of its use in the management of type 2 diabetes mellitus. Drugs, 55, 1998, 563-584.

[30] J.Fuhlendorff, P.Rorsman, and H.Kofod, Stimulation of insulin release by repaglinide and glibenclamide involves both common and distinct processes. Diabetes, 47, 1998, 345-351.

[31] A.Dornhorst, Insulinotropic meglitinide analogues. Lancet, 358, 2001, 1709-1716.

[32] L.A.Witters, The blooming of the French lilac. J. Clin. Invest., 108, 2001, 1105-1107.

[33] M.Nattrass, and K.G.M.M.Alberti, Biguanides. Diabetologia, 14, 1978,71-74.

[34] R.A.Jackson, M.I. Hawa, and J.B.Jaspan, Mechanism of metformin action in non-insulin-dependent diabetes. Diabetes, 36, 1987, 632-640.

[35] C.J.Bailey, and R.C.Turner, Metformin. N. Engl. J. Med., 334, 1996, 574-579.

[36] J.B.Ruige, W.J. Assendelft, and J.M.Dekker, Insulin and risk of cardiovascular disease: a meta-analysis. Circulation, 97, 1998, 9961001.

[37] G.C.Jones, J.P.Macklin, and W.D.Alexander, Contraindications to the use of metformin. BMJ., 326, 2003, 4-5.

[38] M.A.Charles, P.Morange, and E.Eschwege, Effect of weight change and metformin on fibrinolysis and the von Willebrand factor in obese nondiabetic subjects: the BIGPRO1 Study. Biguanides and the Prevention of the Risk Obesity. Diabetes Care, 21, 1998, 1967-1972.

[39] J.B.Buse, M.H.Tan, and M.J.Prince, The effects of oral anti-hyperglycaemic medications on serum lipid profiles in patients with type 2 diabetes. Diabetes Obes. Metab., 6, 2004,133-156.

[40] E.J.Murphy, T.J.Davern, and A.O.Shakil, Troglitazoneinduced fulminant hepatic failure. Acute Liver Failure Study Group. Dig. Dis. Sci., 45, 2000, 549-553.

[41] H.E.Lebovitz, Differentiating members of the thiazolidinedione class: a focus on safety. Diabetes Metab. Res. Rev., 18 (2), 2002, S23-S29.

[42] C.Day, Thiazolidinediones: a new class of antidiabetic drugs. Diabet. Med., 16, 1999, 179-192.

[43] E.R.Higgs, and A.J.Krentz, ABCD position statement on glitazones. Pract. Diabetes Int., 21, 2004, $293-295$.

[44] I.E.Kelly, T.S.Han, and K.Walsh, Effects of a thiazolidinedione compound on body fat and fat distribution of patients with type 2 diabetes. Diabetes Care, 22, 1999, 288-293.

[45] J.A.Balfour, and D.McTavish, Acarbose: an update of its pharmacology and therapeutic use in diabetes mellitus. Drugs, 46, 1993, $1025-1054$.

[46] H.E.Lebovitz, Alpha-Glucosidase inhibitors as agents in the treatment of diabetes. Diabetes Rev., 6, 1998, 132-145.

[47] M.C.Riddle, and D.J.Drucker, Emerging therapies mimicking the effects of amylin and glucagon like peptide 1. Diabetes Care, 29, 2006,435-449.

[48] J.A.Ruggles, D.Kelemen, and A.Baron, Emerging therapies: controlling glucose homeostasis, immunotherapy, islet transplantation, gene therapy, and islet cell neogenesis and regeneration. Endocrinol. Metab. Clin. Noeth. Am., 33(1), 2004, 239-252.

[49] J.J.Holst, Treatment of type 2 diabetes mellitus with agonist of the GLP-1 receptor or DPP-IV inhibitors. Expert Opin. Emerg. Drugs, 9, 2004, 155-166.

[50] B.Ahren, G.Pacini, J.E.Foley, and A.Schweizer, Improved meal related beta cell function and insulin sensitivity by the dipeptidyl peptidase-IV inhibitor vildagliptin in metformin treated patients with type 2 diabetes over 1 year. Diabetes Care, 28, 2005, 19361940.

[51] A.J.Bergman, C.Stevens, Y.Zhou, B.Yi, M.Laethem, and M.De Smet, Pharmacokinetics and pharmacodynamics of sitagliptin, an inhibitor of dipeptidyl peptidase-IV, in healthy subjects: results from two randomized, double-blind, placebocontrolled studies with single oral dose. Clin. Pharmacol. Ther., 78, 2005, 675-688. 